\title{
Inter-relação entre o perfil dos lábios superiores e a posição da maxila e dos incisivos superiores em pacientes adultos
}

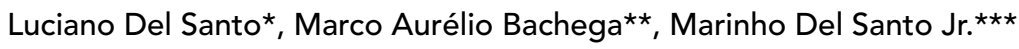

\section{Resumo}

Introdução: tanto as avaliações profissionais quanto as avaliações de pessoas leigas não indicam um claro relacionamento entre as características de perfil duro e do perfil mole em pacientes ortodônticos. Por outro lado, há evidências concretas de que o ortodontista possa alterar o perfil facial de seus pacientes. Objetivos: este trabalho visou mensurar a contribuição das características ósseas da maxila e a inclinação dos incisivos superiores à posição do lábio superior. Métodos: uma amostra de 147 pacientes adultos, 58 homens e 89 mulheres, com idades de 15 a 49 anos, sendo a maioria caucasiana, foi retrospectivamente selecionada na clínica particular de um dos autores. Presumiu-se que o perfil estético facial depende dos tecidos ósseos que o suportam e de sua própria constituição, como espessura, tonicidade e composição. O modelo de pesquisa não havia sido desenhado para controlar as características intrínsecas do tecido mole. Para compor as linhas estéticas de Ricketts e de Burstone, as variáveis cefalométricas de maior interesse foram SNA e U1PP, quando simultaneamente avaliadas. Resultados: os coeficientes de regressão, embora estatisticamente significativos, não contribuíram definitivamente para explicar as variáveis de interesse, as linhas estéticas pré-determinadas. Além disso, os resultados encontrados sugeriram uma correlação negativa entre a posição maxilar (SNA) e a inclinação anteroposterior dos incisivos superiores (U1PP), possivelmente devido às compensações impostas pelos lábios e pela língua. Conclusões: os resultados não apresentaram evidências científicas conclusivas sobre a contribuição dos tecidos duros para o perfil facial de tecido mole.

Palavras-chave: Perfil facial. Perfil labial. Lábio superior.

\section{INTRODUÇÃO E REVISÃO DE LITERATURA}

Há muitas formas de avaliação do perfil facial, entretanto as que têm despertado maior atenção da comunidade ortodôntica são as que expressam o conceito de "beleza" sugerido por pessoas leigas.
De modo geral, as avaliações profissionais apresentam concordância significativa com a opinião de leigos ${ }^{11}$. Entre profissionais, há coerência entre as avaliações de ortodontistas e as de cirurgiões bucomaxilofaciais $^{18}$.

\footnotetext{
* Mestre em Cirurgia e Traumatologia Bucomaxilofacial - HospHel/SP. Especialista em Cirurgia e Traumatologia Bucomaxilofacial - CBCTBMF. Residência em Cirurgia e Traumatologia Bucomaxilofacial pela Universidade Estadual Paulista (Unesp/Araraquara).

** Professor assistente do curso de especialização em Ortodontia da Universidade de Marília/SP. Especialista em Ortodontia pela Sociedade Paulista de Ortodontia (SPO). MBA em Gestão Empresarial pela Fundação Getúlio Vargas (FGV).

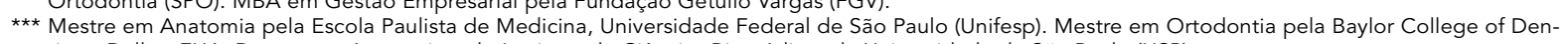
tistry, Dallas, EUA. Doutor em Anatomia pelo Instituto de Ciências Biomédicas da Universidade de São Paulo (USP).
} 
De todas as evidências publicadas, sugere-se que não há correspondência precisa entre as características do perfil duro e do perfil mole de um paciente. Basicamente, o perfil duro considera o tamanho e a posição das bases maxilares e dos dentes, e o perfil mole considera a projeção dos lábios superior e inferior e a projeção de mento mole.

Embora o contorno facial não seja suficiente para se determinar a atratividade da estética facial ${ }^{20}$, ortodontistas podem alterar significativamente o perfil facial ${ }^{12,15}$, por agirem na anatomia dos tecidos duros que suportam os tecidos moles ${ }^{6,19}$.

Em especial, mudanças na inclinação dos incisivos, seja por vestibularização ou lingualização, influenciam diretamente no contorno dos lá-

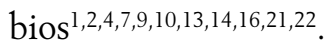

Extrações dentárias, quando corretamente indicadas (protusão labial e apinhamento), promovem expressivo benefício ao perfil facial ${ }^{3}$. Como um exemplo de condução terapêutica com meta bem definida, as extrações de primeiros pré-molares superiores oferecem ótima camuflagem da má oclusão de Classe II, seja dentária ou esquelética.

No contexto do perfil facial, a máxima atenção dos ortodontistas está voltada para o perfil labial. Por isso, duas referências cefalométricas muito populares avaliam a posição dos lábios: a linha estética de Ricketts ${ }^{17}$ e a linha estética de Burstone ${ }^{6}$. É imprescindível salientar que o perfil labial de um indivíduo é resultado de duas principais características do mesmo: os tecidos duros, arcabouço ósseo e dentes, que sustentam o lábio; e suas próprias características intrínsecas como espessura, tonicidade, etnicidade, quantidade e distribuição de tecido adiposo, idade, gênero e hábitos.

A Ortodontia tem dedicado significativa atenção às características e respostas do lábio superior às movimentações dentárias promovidas nos incisivos superiores, e menos atenção às alterações ocorridas nos lábios inferiores, que são sujeitas a outras variáveis, como padrões faciais horizontal e vertical, padrões de deglutição, fonação e respiração e, no caso de tratamento ortodôntico, às terapias aplicadas.

Antes mesmo de se esclarecer os efeitos dos tratamentos ortodônticos sobre o perfil labial, é necessário entender melhor qual é a relação anatômica entre os tecidos duros e os lábios, ao menos os lábios superiores, uma vez que essa relação com os lábios inferiores seguramente embute ainda mais variação e inconsistência do que com os superiores.

Essa variação sempre deve ser rigorosamente acompanhada estatisticamente porque, caso contrário, a falta de evidência científica poderia representar, em última instância, um indesejável empirismo. Se o modelo de pesquisa desenvolvido não é claro e bem definido, as respostas são dúbias e, por isso, pouco proveitosas.

Etnicamente - em indivíduos negros, por exemplo -, além da variação esperada nas características intrínsecas de seus lábios (como espessura, distribuição adiposa, flexibilidade e densidade muscular), seus incisivos superiores são, ao mesmo tempo, anatomicamente vestibularizados.

De um modelo de pesquisa que divide a amostra em subamostras compostas por indivíduos brancos ou negros, podemos testar as diferenças entre as duas raças, mas não podemos elucidar qual é o componente que mais colabora para a projeção dos lábios dos negros: a espessura dos lábios ou a inclinação de seus incisivos.

Outro modelo de pesquisa, o desenvolvido no presente trabalho, é avaliar se a relação entre os tecidos duros e moles é íntima o suficiente para afirmar-se, com relativa segurança, que o perfil labial depende fundamentalmente do perfil ósseo facial. Para testar essa relação, a amostra não deve ser dividida por raça ou gênero, mas sim coletar todos os dados de uma população definida e inter-relacionar suas características cefalométricas de tecido duro com as de tecido mole. Matematicamente, podese estabelecer a intimidade entre as características de variáveis de tecidos duros e variáveis de tecidos moles de uma amostra de indivíduos através de um modelo de regressão linear múltiplo. 


\section{PROPOSIÇÃO}

Este estudo avaliou a contribuição de características ósseas e dentárias maxilares para o perfil do lábio superior, sem filtrar ou controlar a amostra para as variáveis raça ou gênero. Especificamente, o projeto avaliou retrospectivamente a inter-relação entre o perfil do lábio superior e o posicionamento da maxila e dos incisivos superiores em pacientes adultos. A hipótese nula de não haver relação significativa entre o perfil do lábio superior e o perfil duro maxilar foi testada. Além disso, o estudo selecionou as variáveis cefalométricas de perfil duro maxilar que, matematicamente, melhor explicam as características anatômicas dos lábios superiores, e mensurou a correlação entre tais variáveis cefalométricas de perfil duro.

\section{MATERIAL E MÉTODOS}

\section{Amostra}

A amostra foi formada por 147 pacientes, 58 homens e 89 mulheres, submetidos a tratamento ortodôntico na clínica particular de um dos autores. Todos os pacientes que não tinham sido submetidos a cirurgias ortognáticas, que não apresentavam defeitos faciais significativos ou síndromes, e que apresentavam radiografias laterais iniciais com boa qualidade foram retrospectivamente selecionados. A idade dos pacientes variou de 15 a 49 anos (média de 30,1 $\pm 8,3$ anos). Etnicamente, a amostra se constituiu de 127 pacientes brancos, 13 pacientes asiáticos e 6 pacientes negros.

\section{Pontos cefalométricos e variáveis}

Pontos cefalométricos identificados em cada radiografia lateral

1) Sela (S): centro da concavidade óssea da sela túrcica.

2) Násio (N): intersecção da sutura internasal com a sutura frontonasal.

3) Espinha Nasal Anterior (ENA): ponto mais anterior do palato duro; intersecção da parte anterossuperior da maxila com o assoalho da fossa nasal.
4) Espinha Nasal Posterior (ENP): ponto mais posterior do palato duro.

5) Ponto A (A): ponto mais profundo da concavidade anterior da maxila.

6) Incisal do Incisivo Superior: ponto mais inferior da coroa do incisivo superior.

7) Ápice do Incisivo Superior: ponto mais superior da raiz do incisivo central superior.

8) Ponta Nasal: ponto mais anterior do nariz.

9) Ponto Naso-Labial (NL): intersecção entre a base inferior do nariz e o ponto mais superior do lábio superior.

10) Lábio Superior (LS): ponto mais anterior do lábio superior, na borda mais superior do vermelhão do lábio.

11) Pogônio (Pg): ponto mais anterior do tecido mole do mento.

Eixos utilizados

1) Base Craniana: do ponto Sela ao ponto Násio.

2) Palatino: do ponto Espinha Nasal Anterior ao ponto Espinha Nasal Posterior.

3) U1: longo eixo dos incisivos superiores, do ponto incisal ao ponto ápice.

4) NA: do ponto Násio ao ponto A.

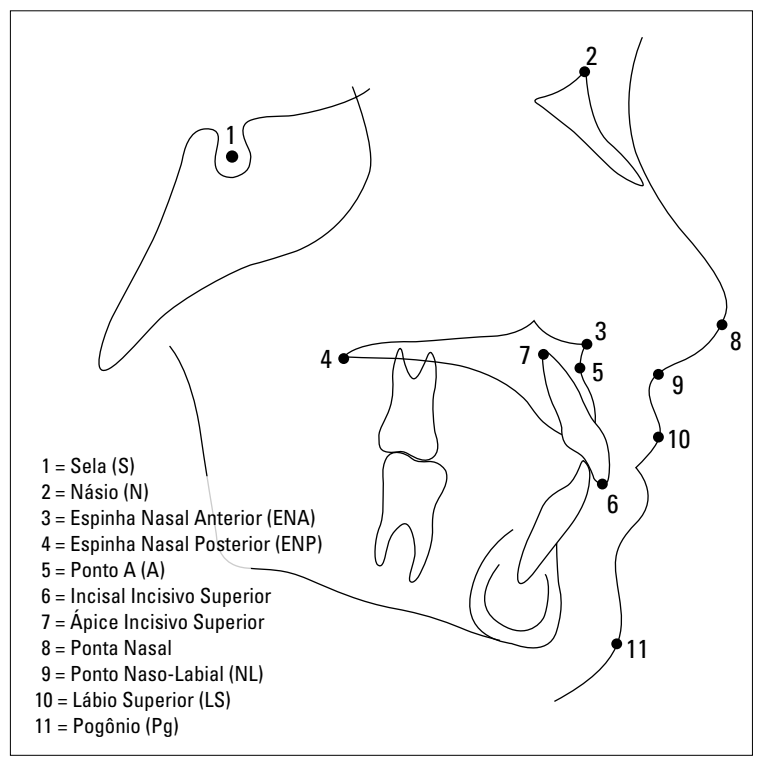

FIGURA 1 - Pontos cefalométricos utilizados. 
Variáveis definidas

1) SNA: ângulo formado pelos pontos Sela (ponto 1), Násio (ponto 2) e Ponto A (ponto 5).

2) UISN: ângulo formado pelo plano da base craniana (SN) e pelo longo eixo dos incisivos superiores (pontos 6 e 7 ).

3) U1NA: ângulo formado pelo longo eixo dos incisivos superiores (pontos 6 e 7) e linha NA (pontos 2 e 5).

4) U1PP: ângulo formado pelo longo eixo dos incisivos superiores (pontos 6 e 7) e o eixo palatino (pontos 3 e 4 ).

5) LSE: distância do lábio superior (ponto 10) à linha estética (pontos 8 a 11, linha que une o ponto mais anterior do nariz ao ponto mais anterior do mento mole).

6) LSB: distância do lábio superior (ponto 10) à linha de Burstone (pontos 9 a 11, linha que une o ponto naso-labial ao ponto mais anterior do mento mole).

7) NL (ângulo naso-labial): formado pela linha que tangencia a base inferior do nariz e a linha que tangencia o contorno mais superior do lábio superior, unidas no ponto 9 .

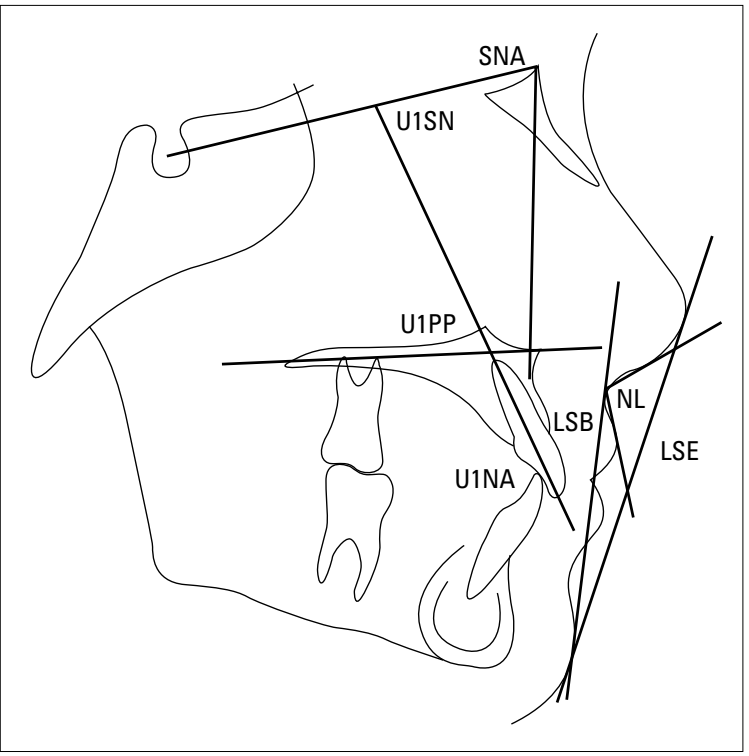

FIGURA 2 - Variáveis utilizadas.

\section{Coleta de dados}

As radiografias laterais foram traçadas pelo mesmo pesquisador, com lapiseira $0,3 \mathrm{~mm}$; em papel acetato para traçados ortodônticos. As radiografias foram digitalizadas em mesa digitalizadora com o software DFPlus (Dentofacial Software Inc., Ontario, Canadá).

\section{Grau de confiabilidade}

Uma subamostra de 15 pacientes, aleatoriamente escolhidos, foi retraçada e redigitalizada pelo mesmo pesquisador e com o mesmo método, com um intervalo de uma semana, para se calcular a confiança intraobservador.

O erro sistemático não foi estatisticamente significativo para nenhuma das variáveis (nível de significância de $\mathrm{p} \leq 0,05$ ), confirmando a validação da confiabilidade intraobservador. O erro aleatório, definido de acordo com a fórmula de Dahlberg $^{8}\left(\sqrt{ } \sum \mathrm{d}^{2} / 2 \mathrm{n}\right)$, foi de, no máximo, $0,37^{\circ}$, identificado para a variável NL.

\section{Análise estatística}

Todos os dados estatísticos foram processados pelo software SPSS 10.0 (Chicago, EUA). Médias e desvios-padrões foram calculados para todas as variáveis. Todas as variáveis apresentaram distribuição normal (homoscedasticidade).

Modelos de regressão linear múltipla foram testados, selecionando-se "passo a passo" (stepwise) as variáveis regressoras que melhor contribuíam para cada modelo testado.

As variáveis de interesse testadas foram: LSE, LSB e NL. As variáveis regressoras testadas foram: SNA, U1SN, U1NA e U1PP. Os parâmetros de probabilidade $\mathrm{F}$ foram definidos em 0,05 para entrada e 0,10 para remoção da variável em cada modelo de regressão. $\mathrm{O}$ grau de significância ANOVA foi estabelecido como significativo se $p$ $\leq 0,05$.

Coeficientes de correlação foram apresentados para as variáveis selecionadas em cada modelo.

Os modelos de regressão linear múltipla segui- 
TABELA 1 - Medidas de tendência central, variáveis de interesse.

$\begin{array}{cccc}\text { VARIÁVEL } & \text { NL }\left(^{\circ}\right) & \text { LSE }(\mathrm{mm}) & \text { LSB }(\mathrm{mm}) \\ \text { média } & 107,0 & -3,2 & 4,3 \\ \begin{array}{l}\text { desvio- } \\ \text { padrão }\end{array} & 13,9 & 3,3 & 2,3\end{array}$

TABELA 2 - Medidas de tendência central, variáveis regressoras.

$\begin{array}{ccccc}\text { VARIÁVEL } & \text { SNA }\left({ }^{\circ}\right) & \text { U1SN }\left({ }^{\circ}\right) & \operatorname{U1PP}\left({ }^{\circ}\right) & \text { U1NA }\left(^{\circ}\right) \\ \text { média } & 82,9 & 104,2 & 113,8 & 21,3 \\ \begin{array}{c}\text { desvio- } \\ \text { padrão }\end{array} & 4,2 & 7,6 & 6,8 & 7,0\end{array}$

TABELA 3 - Relação entre variáveis de interesse e variáveis regressoras.

\begin{tabular}{|c|c|c|c|c|c|}
\hline MODELO & \multicolumn{2}{|c|}{ LSE (mm) } & \multicolumn{2}{|c|}{ LSB (mm) } & NL $\left({ }^{\circ}\right)$ \\
\hline variável(is) regressora(s) & SNA & SNA/U1PP & U1PP & U1PP/SNA & U1SN \\
\hline e valor $\mathrm{R}$ & 0,23 & 0,29 & 0,30 & 0,38 & 0,18 \\
\hline ANOVA & $0,005^{* *}$ & $0,002 * *$ & $0,001 * * *$ & $0,001 * * *$ & $0,028 *$ \\
\hline $\begin{array}{l}\text { * Significância em nível } \\
\text { * Significância em nível } \\
* \text { * Significância em nível }\end{array}$ & $\begin{array}{l}\leq 0,05 \\
\leq 0,01 \\
\leq 0,001\end{array}$ & & & & \\
\hline
\end{tabular}

TABELA 4 - Coeficientes de correlação entre as variáveis regressoras.

\begin{tabular}{cc} 
CORRELAÇÃO & SNA e U1/PP \\
\hline Variável LSE & $-0,17$ \\
\hline Variável LSB & $-0,17$ \\
\hline
\end{tabular}

ram a seguinte equação:

$$
[Y=\beta 0+\beta 1+\beta 2+\beta 3+\epsilon]
$$

Sendo:

$\mathrm{Y}=$ Variável de Interesse;

$\beta=$ Coeficiente de Variável Regressora;

$\epsilon=$ Erro.

\section{RESULTADOS}

Dados descritivos das variáveis de interesse e variáveis regressoras são descritos nas tabelas 1 e 2 .

Para as variáveis de interesse LSE e LSB, cálculos de regressão selecionaram as variáveis SNA e U1PP (em negrito, Tab. 3). Para a variável de interesse NL, a única variável regressora escolhida foi UISN (Tab. 3).

Dados descritivos das variáveis de interesse e variáveis regressoras são descritos nas tabelas 1 e 2 .

Os modelos matematicamente mais adequados, para ambas as variáveis de interesse, foram compostos por duas variáveis regressoras. Os coe- ficientes de correlação entre essas variáveis regressoras são descritos na tabela 4 .

\section{DISCUSSÃO}

Não há na literatura conclusões definitivas sobre a relação entre o perfil facial duro e o perfil facial mole de pacientes ortodônticos. De modo geral, há uma tendência dos profissionais em se desvalorizar avaliações cefalométricas em detrimento da avaliação facial dos indivíduos. Obviamente que a avaliação do perfil mole é um importante componente do diagnóstico ortodôntico e, muitas vezes, o fator decisivo para a tomada de importante decisão terapêutica como, por exemplo, as extrações dentárias.

Entretanto, melhor do que se condenar abruptamente valores cefalométricos é entender como resultados cefalométricos têm sido rotineiramente apresentados na literatura e as importantes limitações dos modelos de pesquisa que os geraram. Assim, o leitor, consumidor final dos dados apresentados, estará ciente dos erros sistemáticos e metodológicos envolvidos e, principalmente, de seus efeitos.

Indivíduos com diferentes idades, gêneros e características étnicas, além de serem diferentes entre si per se (cada grupo é diferente de outros grupos), respondem de forma diferente aos 
tratamentos propostos ${ }^{5}$. E os principais fatores envolvidos nessa diferença foram: espessura dos lábios e inclinação dos incisivos.

Os modelos de regressão múltipla testados melhor evidenciaram que os incisivos superiores contribuem para dar suporte aos lábios superiores se sua posição anteroposterior (aqui representada pelo ângulo SNA) e sua inclinação anteroposterior (aqui representada pelo ângulo U1PP) são simultaneamente consideradas (Tab. 3).

Interessante notar a correlação negativa entre a posição anteroposterior dos incisivos e sua inclinação (Tab. 4). Essa correlação negativa é explicada pela ação natural de compensação muscular, camuflando más oclusões, muitas vezes esqueléticas, pela adaptação da posição dos incisivos.

Com a harmonização das pressões musculares da língua e dos lábios, quando os incisivos superiores estão anatomicamente vestibularizados, inseridos ou não em maxilas anatomicamente anteriorizadas, são mais sujeitos à pressão labial, que tende a retroincliná-los. Da mesma forma, incisivos anatomicamente lingualizados, inseridos ou não em maxilas anatomicamente retruídas, estão mais sujeitos à ação da língua, que tende a projetálos anteriormente.
As variáveis regressoras, quando individualmente consideradas, podem atuar como uma covariável, isto é, ao não serem controladas, confundem o quanto o perfil duro influencia o perfil mole. Isso porque, em potencial, a inclinação anterior dos incisivos pode, estatisticamente, neutralizar a projeção anterior da maxila.

\section{CONCLUSÕES}

Baseando-se nos resultados apresentados, é possível concluir que:

1) Os resultados encontrados não embutem suficiente evidência para rejeitar a hipótese nula de não haver substantiva relação entre o perfil do lábio superior e o perfil duro maxilar.

2) Matematicamente, as variáveis cefalométricas de perfil duro maxilar que melhor explicam o perfil do lábio superior, embora sem significativa clareza, são SNA e U1PP simultaneamente consideradas pela equação regressora.

3) Há discreta correlação negativa entre a posição e a angulação dos incisivos superiores, devido às pressões musculares dos lábios e da língua.

\title{
Inter-relationship between the upper lip and the maxillary positioning with upper incisors in adult patients
}

\begin{abstract}
Introduction: Professional evaluations and lay person evaluations as well do not show a clear relationship between hard tissue and soft tissue profiles in orthodontic patients. However, there are concrete evidences that the orthodontist can change the facial profile of the patients. Aim: This research project aimed to measure the contribution of the bone structure of the maxilla and the upper incisors inclination to the upper lip profile. Methods: A sample of 147 adult patients, 58 male and 89 female, aged from 15 to 49 years, the most of them Caucasians, was retrospectively selected from the private practice of one of the authors. It was assumed that the esthetic facial profile depends of the hard tissues that support it besides its own features as thickness, strength and composition. The present research model was not set to control the intrinsic features of the soft tissue. To compose the Ricketts and Burstone esthetic lines, the main cephalometric variables were SNA and U1PP, when concomitantly considered. Results: The regression coefficients, although statistically significant, did not contributed expressively to explain the regard variables, the pre-defined esthetic lines. Furthermore, the results suggested a negative correlation between the maxillary position (SNA) and the anteroposterior inclination of the upper incisors (U1PP), possibly due to the compensatory action of the lips and the tongue. Conclusion: The results did not presented conclusive scientific evidences about the contribution of the hard tissues for the soft tissue facial profiles.
\end{abstract}

Keywords: Facial profile. Labial profile. Upper lip. 


\section{REFERÊNCIAS}

1. BISHARA, S. E.; CUMMINS, D. M.; JAKOBSEN, J. R.; ZAHER, A. R. Dentofacial and soft tissue changes in Class II, division 1 cases treated with and without extractions. Am. J. Orthod. Dentofacial Orthop., St. Louis, v. 107, no. 1, p. 28-37, 1995.

2. BLOOM, L. A. Perioral profile changes in orthodontic treatment. Am. J. Orthod., St. Louis, v. 47, no. 5, p. 371-379, 1961.

3. BOWMAN, S. J.; JOHNSTON, L. E. The esthetic impact of extraction and nonextraction treatments on Caucasian patients. Angle Orthod., Appleton, v. 70, no. 1, p. 3-10, 2000.

4. BRAVO, L. A. Soft tissue facial profile changes after orthodontic treatment with four premolars extracted. Angle Orthod., Appleton, v. 64, no. 1, p. 31-41, 1994.

5. BROCK, R. A.; TAYLOR, R. W.; BUSCHANG, P. H.; BEHRENTS, R. G. Ethnic differences in upper lip response to incisor retraction. Am. J. Orthod. Dentofacial Orthop., St. Louis, v. 127, no. 6, p. 683-691, 2005.

6. BURSTONE, C. J. Integumental contour and extension patterns. Angle Orthod., Appleton, v. 29, no. 2, p. 93-104, 1959

7. CUMMINS, D. M.; BISHARA, S. E.; JAKOBSEN, J. R. A computer assisted photogrammetric analysis of soft tissue changes after orthodontic treatment. Part II: Results. Am. J. Orthod. Dentofacial Orthop., St. Louis, v. 108, no. 1, p. 38-47, 1995.

8. DAHLBERG, G. Statistical methods for medical and biological students. London: George Allen and Unwin, 1940.

9. HERSHEY, H. G. Incisor tooth retraction and subsequent profile change in postadolescent female patients. Am. J. Orthod. St. Louis, v. 61, no. 1, p. 45-54, 1972.

10. HOLDAWAY, R. A. A soft tissue cephalometric analysis and its use in orthodontic treatment planning: Part I. Am. J. Orthod. St. Louis, v. 84, no. 1, p. 1-28, July 1983.

11. MAPLE, J. R.; VIG, K. W. L.; BECK, F. M.; LARSEN, P. E.; SHANKER, $S$. A comparison of providers' and consumers' perceptions of facial attractiveness. Am. J. Orthod. Dentofacial Orthop., St. Louis, v. 128, no. 6, p. 690-696, Dec. 2005.

12. MERGEN, J. L.; SOUTHARD, K. A.; DAWSON, D. V.; FOGLE, L. L.; CASKO, J. S.; SOUTHARD, T. E. Treatment outcomes of growing Class II division 1 patients with varying degrees of anteroposterior and vertical dysplasias. Part 2. Profile silhouette evaluation. Am. J. Orthod. Dentofacial Orthop., St. Louis, v. 125 , no. 4, p. 457-462, Apr. 2004.
13. OLIVER, B. M. The influence of lip thickness and strain on upper lip response to incisor retraction. Am. J. Orthod., St. Louis, v. 82 , no. 2, p. 141-149, 1982

14. PARK, S.; KUDLICK, E. M.; ABRAHAMIAN, A. Vertical dimensional changes of the lips in the North American black patient after four first-premolar extractions. Am. J. Orthod. Dentofacial Orthop., St. Louis, v. 96, no. 2, p. 152-160, 1989.

15. QUINTÃO, C.; HELENA, I.; BRUNHARO, V. P.; MENEZES, R. C.; ALMEIDA, M. A. O. Soft tissue facial profile changes following functional appliance therapy. Eur. J. Orthod., Oxford, v. 28, no. 1, p. 35-41, Feb. 2006.

16. RAINS, M. D.; NANDA, R. Soft tissue changes associated with maxillary incisor retraction. Am. J. Orthod., St. Louis, v. 81, no. 6, p. 481-488, 1982.

17. RICKETTS, R. M. Cephalometric analysis and synthesis. Angle Orthod., Appleton, v. 31, no. 3, p. 141-156, 1961.

18. SOH, J.; CHEW, M. T.; WONG, H. B. Professional assessment of facial profile attractiveness. Am. J. Orthod. Dentofacial Orthop., St. Louis, v. 128, no. 2, p. 201-205, 2005.

19. SUBTELNY, J. D. A longitudinal study of soft tissue facial structures and their profile characteristics, defined in relation to underlying skeletal structures. Am. J. Orthod., St. Louis, v. 45, no. 7, p. 481-508, 1959.

20. SYROPOULOS, M. N.; HALAZONETIS, D. J. Significance of the soft tissue profile on facial esthetics. Am. J. Orthod. Dentofacial Orthop., St. Louis, v. 119, no. 5, p. 464-471, 2001

21. TALASS, M. F.; TALASS, L.; BAKER, R. C. Soft tissue profile changes resulting from retraction of maxillary incisors. Am. J. Orthod. Dentofacial Orthop., St. Louis, v. 91, no. 5 p. 385-394, 1987.

22. WISTH, P. J. Soft tissue response to upper incisor retraction in boys. Br. J. Orthod., Oxford, v. 1, no. 5, p. 199-204, Oct. 1974.
Endereço para correspondência

Luciano Del Santo

Av. Vereador José Diniz 3.725, conj. 81 - Campo Belo

CEP: 04.603-004 - São Paulo / SP

E-mail: luciano@neoface.com.br 